\title{
ANTIBIOTIC RESISTANCE OF THE NASOPHARYNX MICROBIOTA IN PATIENTS WITH INFLAMMATORY PROCESSES
}

DOI: 10.36740/WLek202007120

\author{
Tetiana V. Ivakhniuk', Viktoriia M. Holubnycha' ${ }^{1}$, Vladyslav A. Smiianov ${ }^{1}$, Lesia A. Rudenko ${ }^{2}$, Yevgen V. Smiianov ${ }^{1}$ \\ 'SUMY STATE UNIVERSITY, SUMY, UKRAINE \\ 2ALUNA PUBLISHING HOUSE, KONSTANCIN-JEZIORNA, POLAND
}

\begin{abstract}
The aim: To study the species composition of microorganisms isolated from patients with inflammatory processes of different localization and to monitor the sensitivity of isolated microorganisms to the most commonly used antibiotics.

Materials and methods: During 2017-2019, we examined 517 patients with acute inflammatory processes of the nasopharynx. To establish the etiological structure of pathogens of inflammatory processes, a microbiological study of nasopharyngeal washes was carried out using classical methods of isolation and identification of microorganisms. The sampling of the test material from patients was performed during the first visit to a doctor, before the appointment and implementation of etiopathogenetic therapy. To study the sensitivity of isolated microorganisms to antibacterial drugs, we used the method of paper disks (manufactured by "Pharmaktiv" Ltd. (Kyiv, Ukraine) and Himedia (India). Results and conclusions: The microflora of the mucous membranes of the nose and throat in patients with acute inflammatory processes of the nasopharynx is represented mainly by monoisolates of staphylococci and streptococci. The sensitivity of isolated microorganisms to antibiotics varied between different types of microorganisms and between different antibiotics. Cefazolin showed efficacy against all types of microorganisms. K. pneumonia strains showed the highest antibiotic resistance. Among the gram-positive cocci, 18 strains (4.2\%) resistant to all antibiotics were isolated, which can be regarded as the circulation of hospital strains outside the medical institutions.
\end{abstract}

KEY WORDS: antibiotics, resistance, microflora, nose, throat

Wiad Lek. 2020;73(7):1415-1419

\section{INTRODUCTION}

Despite significant achievements in medicine, infectious diseases remain one of the leading causes of morbidity and mortality worldwide [1]. According to the statistical reports of the Sanitary and Epidemiological Service, over the past 20 years of observation, infectious diseases have affected from 7 to 10 million residents of Ukraine annually. The share of childhood infections in the overall morbidity structure has a steady upward trend (from $49.1 \%$ in 1995 to $65.4 \%$ in 2013) with a significant increase in both viral and bacterial infections [2]. The only option of etiotropic therapy that can curb the infectious process, prevent the development of complications and contribute to the rapid health improvement of patients [3] is the use of antibiotics. It is noted that their use has increased by $40 \%$ worldwide over the last decade [4]. However, in his article L. L. Founou [5] noted that antibiotics have become «endangered species» at risk due to the rapid spread of antibiotic resistance worldwide [6]. It is known that genes responsible for the formation of resistance can enter the bacterial population from commensals (non-pathogenic representatives) and from microorganisms living in the environment. Therefore, to understand the mechanisms of acquisition and spread of antibiotic resistance among pathogenic bacteria fully, it is necessary to study the entire microbiota carefully [1]. Scientific advances in recent years have significantly deepened the knowledge about the biological properties of pathogens, their genetic characteristics, adaptive variability, the ability to persist on biotic and abiotic objects in the composition of biofilms, and to create associations of pathogenic, conditionally pathogenic bacteria with representatives of normofloor bacteria [7]. However, the problems of diagnosis and treatment of purulent-inflammatory diseases remain relevant and diverse. An important step in the prevention of complications and chronicity of purulent-inflammatory processes is the monitoring of the species composition and antibiotic resistance of microorganisms that are released from patients and from epidemiologically significant objects of the internal environment of medical institutions.

\section{THE AIM}

To study the species composition of microorganisms isolated from patients with inflammatory processes of different localization and to monitor the sensitivity of isolated microorganisms to the most commonly used antibiotics.

\section{MANUALS AND METHODS}

During 2017-2019, we examined 517 patients with acute inflammatory processes of the nasopharynx, 350 (pharynx) 
Table1. Specific structure of pathogens of purulent-inflammatory processes of patients with acute inflammatory processes of the nasopharynx

\begin{tabular}{|c|c|c|c|c|c|c|}
\hline \multirow{3}{*}{ Kind of microorganism } & \multicolumn{6}{|c|}{ The number of isolated microorganisms } \\
\hline & \multicolumn{2}{|c|}{$\begin{array}{l}\text { from the throat } \\
\qquad(n=401)\end{array}$} & \multicolumn{2}{|c|}{$\begin{array}{l}\text { from the nose } \\
\qquad(n=167)\end{array}$} & \multicolumn{2}{|c|}{$\begin{array}{l}\text { Totally } \\
(n=568)\end{array}$} \\
\hline & abs & $\%$ & abs & $\%$ & abs & $\%$ \\
\hline S. aureus & 98 & 24,5 & 100 & 59,9 & 198 & 34,9 \\
\hline S. pyogenes & 129 & 32,2 & 54 & 32,3 & 183 & 32,2 \\
\hline Candida spp. & 64 & 15,9 & - & 0 & 64 & 11,3 \\
\hline K. pneumoniae & 57 & 14,2 & - & 0 & 57 & 10,0 \\
\hline S. haemoliticus & 43 & 10,7 & 13 & 7,8 & 56 & 9,9 \\
\hline K. ozaenae & 7 & 1,7 & - & 0 & 7 & 1,2 \\
\hline Moraxella spp. & 3 & 0,8 & - & 0 & 3 & 0,5 \\
\hline
\end{tabular}

Table 2. The sensitivity of isolated microorganisms to antibiotics.

\begin{tabular}{|c|c|c|c|c|c|c|c|c|}
\hline \multirow[b]{2}{*}{$\begin{array}{c}\text { Kind of } \\
\text { microorganism }\end{array}$} & \multicolumn{8}{|c|}{ The relative number of strains (\%) sensitive to antibiotics } \\
\hline & 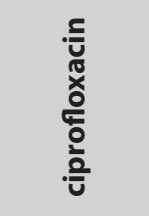 & 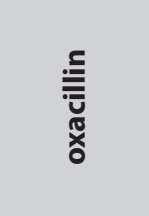 & 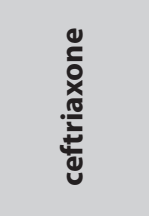 & 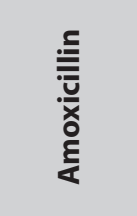 & 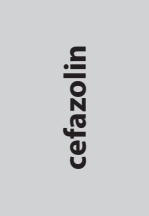 & 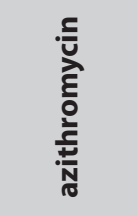 & 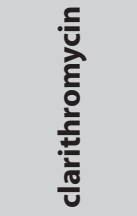 & 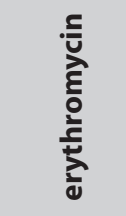 \\
\hline S. aureus, $\mathrm{n}=198$ & $56,0 \pm 0,3$ & $56,1 \pm 0,3$ & $72,2 \pm 0,3$ & $45,9 \pm 0,6$ & $62,6 \pm 0,4$ & $42,9 \pm 0,6$ & $54,1 \pm 0,3$ & $45,9 \pm 0,3$ \\
\hline S. haemoliticus, $\mathrm{n}=43$ & $58,7 \pm 1,1$ & $53,5 \pm 1,1$ & $84,0 \pm 0,9$ & $80,0 \pm 0,9$ & $65,1 \pm 1,1$ & $66,7 \pm 1,1$ & $76,7 \pm 1,0$ & $27,9 \pm 1,0$ \\
\hline S. pyogenes, $\mathrm{n}=183$ & $74,9 \pm 0,3$ & $46,4 \pm 0,6$ & $63,4 \pm 0,4$ & $33,3 \pm 0,8$ & $49,2 \pm 0,6$ & $78,7 \pm 0,3$ & $48,6 \pm 0,6$ & $42,1 \pm 0,6$ \\
\hline K. pneumoniae, $\mathrm{n}=57$ & $37,9 \pm 0,9$ & $10,0 \pm 0,5$ & $11,6 \pm 0,6$ & $9,3 \pm 0,5$ & $41,9 \pm 0,9$ & $8,5 \pm 0,5$ & $5,4 \pm 0,4$ & $7,0 \pm 0,4$ \\
\hline K. ozaenae, $\mathrm{n}=7$ & $14,3 \pm 5,8$ & - & 0 & $28,6 \pm 7,5$ & $71,4 \pm 7,5$ & $57,1 \pm 8,2$ & - & - \\
\hline Moraxella spp., $\mathrm{n}=3$ & $33,3 \pm 23,6$ & $33,3 \pm 23,6$ & $33,3 \pm 23,6$ & 0 & $66,7 \pm 23,6$ & 0 & - & - \\
\hline
\end{tabular}

and 167 (nose). Patients underwent comprehensive examination in accordance with standards of care. The examination procedure for these individuals was conducted in accordance with the standards of the ethics committee. To establish the etiological structure of pathogens of inflammatory processes, a microbiological study of nasopharyngeal washes was carried out on the basis of the microbiological laboratory of Sumy State University using classical methods of isolation and identification of microorganisms. The sampling of the test material from patients was performed during the first visit to a doctor, before the appointment and implementation of etiopathogenetic therapy. To study the sensitivity of isolated microorganisms to antibacterial drugs, we used the method of paper disks (manufactured by "Pharmaktiv" Ltd. (Kyiv, Ukraine) and Himedia (India). The results of the studies were subjected to statistical analysis. Graph Pad Quik Calcs was used to calculate the t-Student test.

\section{RESULTS}

On the basis of clinical and epidemiological data, the following diagnoses were previously established for patients: $43.1 \%$ of tonsillitis cases; $15.7 \%$ - sore throat;
$32.3 \%$ - rhinosinusitis; $8.9 \%$ are adenoids, rhinopharyngitis. In total,401 strains of microorganisms from the pharynx and 167 from the nose were isolated and identified. The frequency of isolation of microorganisms in a monoculture from the pharynx was $90.9 \%$ (318 isolates), from the nose $-100 \%$ (167 strains). Microbial associations were isolated in 32 patients $(9.1 \%$ of patients examined) from the throat. The specific structure of pathogens of purulent-inflammatory processes is presented in table 1.

When studying the frequency of occurrence of various taxa of microorganisms in a clinically significant amount ( $\geq 106 \mathrm{CFU} / \mathrm{ml}$ of wash from a swab) in the studied biotopes, it was found that microorganisms isolated from the mucous membrane of the pharynx were represented by 5 genera, from the nasal mucosa -3 genera (Table 1 ).

In the general structure of the species spectrum, S. aureus took the first place (34.9\%) and was dominant in the material from the nose (59.9\%). It should be noted that S. aureus is considered a transient representative of the microflora of the nose and this result indicates a significant spread in the population of carriers of pathogenic staphylococcus. In the frequency of discharge from the mucous membrane, the first place was taken by a representative of the genus Streptococcus - S. pyogenes (32.2\%). The obtained result 
Table 3. Resistance profiles of isolated microorganisms

\begin{tabular}{|c|c|c|}
\hline $\begin{array}{c}\text { Kind of microorganisms, } \\
\text { quantity }\end{array}$ & Profile of antibiotic resistance & $\begin{array}{c}\text { The relative number } \\
\text { of polyresistant strains, \% }\end{array}$ \\
\hline \multirow{8}{*}{ S. aureus, $\mathrm{n}=198$} & $\mathrm{Z} \square \square \mathrm{OA} \square \mathrm{E} \square$ & 19,1 \\
\hline & $\square \mathrm{C} \square \square \mathrm{AK} \square \square$ & 6,0 \\
\hline & $\square \mathrm{CI} \square \mathrm{AK} \square \square$ & 4,0 \\
\hline & ZCIOAKEF & 5,6 \\
\hline & $\mathrm{Z} \square \mathrm{I} \square \mathrm{A} \square \square \square$ & 3,0 \\
\hline & ZC $\square \square \square \square \square F$ & 2,5 \\
\hline & $\square \square \mathrm{I} \square \mathrm{A} \square \square \mathrm{F}$ & 2,0 \\
\hline & $\square \square \square \mathrm{A} \square \square \square \mathrm{F}$ & 1,5 \\
\hline \multirow{4}{*}{ S. haemoliticus, $\mathrm{n}=43$} & $\square \square \mathrm{IO} \square \square \mathrm{E} \square$ & 11,6 \\
\hline & $\square \square \square \mathrm{O} \square \square \mathrm{EF}$ & 9,3 \\
\hline & $\square \square \mathrm{IAK} \square \square$ & 6,9 \\
\hline & ZCIOAKEF & 4,7 \\
\hline \multirow{8}{*}{ S. pyogenes, $\mathrm{n}=183$} & $\square \mathrm{C} \square \mathrm{OA} \square \mathrm{E} \square$ & 10,9 \\
\hline & $\square \square I \square A K \square \square$ & 1,1 \\
\hline & $\square \mathrm{CIOA} \square \mathrm{E} \square$ & 4,4 \\
\hline & $\square C \square$ ОАК $\square \square$ & 2,7 \\
\hline & $\square \square \square \mathrm{OAKEF}$ & 3,3 \\
\hline & ZCIOAKEF & 2,7 \\
\hline & $\mathrm{Z} \square \mathrm{I} \square \mathrm{A} \square \square \square$ & 3,3 \\
\hline & $\square \mathrm{CI} \square \mathrm{A} \square \square \square$ & 1,1 \\
\hline \multirow{4}{*}{ K. pneumonia, $\mathrm{n}=57$} & $\square C \square \mathrm{OA} \square \square \square$ & 14,0 \\
\hline & ZC $\square$ ОАК $\square \square$ & 14,0 \\
\hline & $\square \square \square \mathrm{OAKEF}$ & 15,8 \\
\hline & $\mathrm{Z} \square \mathrm{I} \square \mathrm{A} \square \mathrm{E} \square$ & 5,3 \\
\hline
\end{tabular}

makes it possible to re-evaluate the pathogenic potential of this microorganism, since it is a representative of the normal microflora of the respiratory tract and under certain conditions can cause purulent-inflammatory processes in the respiratory tract. Candida (15.9\%) was on the third place according to the frequency of excretion. The fourth was Klebsiella pneumoniae (14.2\%). Analyzing the results of microbiological examination of the pharyngeal material from patients with ENT pathology, it should be noted that in all cases of isolation of associations of microorganisms were observed 2 or 3 component fungal-bacterial complexes. In $13(3.7 \%)$ patients, S. aureus and Sandida spp .; in $16(4.6 \%)-S$. aureus, K. pneumonia and Sandida spp., in $3(0.85 \%)-S$. pyogenes and Sandida spp.

Our results differ from the data of Krasii N.I. [7], who primarily selected representatives of the Enterobacteriaceae family $(59.7 \pm 2.2) \%$ from the oropharynx of patients from the Department of Anesthesiology and Intensive Care, while staphylococci were only $(10.6 \pm 1.4) \%$. This difference is probably due to the fact that the mucous membranes of the oropharynx of patients in the intensive care unit were colonized by nosocomial strains, and in our study, mainly conditionally pathogenic representatives of the autochthonous microflora of the nose and pharynx were isolated from the patients.

The need for studying the species composition of microbiota and for exploring the sensitivity of microorganisms to antibiotics is considered a key link in effective therapy of infectious pathology. However, in practice doctors are more likely to perform empirical antibiotic therapy relying on the choice of drugs on world and local antibiotic resistance data. Therefore, constant monitoring of the species composition of the microbiota and its sensitivity to antibacterial drugs should be carried out at all levels - international, national, regional and local. Although the sensitivity of microorganisms to antibiotics varies greatly in different countries, regions, and even medical institutions, there is an idea of a group of problem microorganisms (ESKAPE - Enterococcus faecium, Staphylococcus aureus, Klebsiella pneumoniae, Acinetobacter baumannii, whose Pseudomonas aeruginosa and Enterobacter are studied) which take significantly more attention. Our results indicate a known prevalence among patients with inflammatory processes of the nasopharynx of some representatives from the ESKAPE 
group, which once again confirms the need for a thorough study of their antibiogram. When studying sensitivity to antibiotics, we selected antibiotics with different mechanisms of action, and therefore, different genetic mechanisms are usually involved in the formation of resistance to them. The results of a study of the sensitivity of isolated microorganisms to antibiotics are shown in table 2.

As can be seen from the above (Table 2), the most active antibiotic against all tested microorganisms is cefazolin, to which were sensitive from $41.9 \%$ to $71.4 \%$ of microorganisms. Among the bacteria of the strain K. pneumoniae were most often resistant to different mechanism of action of antibiotics (from 95.6 to $58.2 \%$ resistant isolates). Particular attention is drawn to the isolation of a large number of strains with multiple antibiotic resistance $-49.1 \%$ of $K$. pneumoniae isolates, $32.6 \%$ of S. haemoliticus isolates, $36.9 \%$ of S. aureus isolates, $30.6 \%$ of $S$. pyogenes isolates. Due to the fact that monoinfection does not always appear in the structure of pathogens of purulent-inflammatory processes in patients with acute inflammatory processes of the nasopharynx, therapy should be carried out taking into account the sensitivity of pathogens to antibiotics. On the other hand, the lack of microbiological examination of the material from patients and the results of the antibiogram may lead to complications of fungal etiology. According to the results of studies, it was found that in $6.2 \%$ of cases from the mucous membrane of the pharynx of patients with ENT pathology, bacterial-fungal associations are found. Moreover, Candida spp. isolated in association with bacteria showed a high level of resistance to antifungal drugs: $96.9 \%$ of the strains were resistant to nystatin, $56.3 \%$ to itraconazole, $46.9 \%$ to clotrimazole, $34.4 \%$ to ketoconazole, $21.9 \%$ fluconazole.

To understand fully the trends of the formation of antibiotic resistance, we have formed bacterial resistance profiles that display a set of inherent and acquired resistance genes of a particular clonal population. Antibiotic resistance profiles are isolate markers that can be used for epidemiological analysis of pathogens and to determination patterns of their circulation. The formed resistance profile was as follows: $\mathrm{Z}$ (azithromycin), C (ceftriaxone), I (ciprofloxacin), B (oxycycline), and (amoxicillin), K (clarithromycin), E (erythromycin), F (cefazolin). When interpreting the profile, a capital letter indicates the resistance of the strain to antibiotic or moderate sensitivity, $\square-$ the sensitivity of the microorganism to the antibiotic. Our data are presented in table 3.

As we can see from the table, 24 profiles were detected among the microorganisms with multiple resistance. One hundred fifteen $(23.9 \%)$ strains were resistant to 4 or more antibiotics. Among staphylococci, $10.3 \%$ of strains were resistant to all antibiotics, including oxacillin. Among Klebsiella, $29.8 \%$ of isolates were resistant to 5 antibiotics, including 3 generation cephalosporins. Five strains of streptococci were resistant to all antibiotics. The isolation of strains of microorganisms with the same antibiotic resistance profiles (strains in which the diameters of growth retardation zones around the discs with the same antibiotics are the same or differ by no more than $3 \mathrm{~mm}$ ) from patients and from external objects of medical establishments may indicate their hospital origin. In addition, it is believed that hospital strains of microorganisms have multiple resistance, at least up to 5 antibiotics. Marker for staphylococci is resistance to methicillin (oxacillin) and / or vancomycin, and for enterobacteria to gentamicin and / or cephalosporin antibiotics of the III-IV generations. According to our results, we can assume the circulation of hospital strains in patients undergoing outpatient treatment. Since the likelihood of infection in a hospital was minimal, we can talk about the spread of hospital isolates outside the institution. This indicates a negative trend in the spread of hospital strains that require a more careful and balanced administration of antibiotics, taking into account the antibiogram.

\section{CONCLUSION}

The microflora of the mucous membranes of the nose and throat in patients with acute inflammatory processes of the nasopharynx is represented mainly by monoisolates of staphylococci and streptococci. The sensitivity of isolated microorganisms to antibiotics varied between different types of microorganisms and between different antibiotics. Cefazolin showed efficacy against all types of microorganisms. K. pneumonia strains showed the highest antibiotic resistance. Among the gram-positive cocci, 18 strains (4.2\%) resistant to all antibiotics were isolated, which can be regarded as the circulation of hospital strains outside the medical institutions.

\section{REFERENCES}

1. S.A. Derkach Microbiological aspects of treatment of purulentinflammatory diseases. Infectious diseases. 2015;4 (82):5-15.

2. Global antibiotic consumption 2000 to 2010: an analysis of national pharmaceutical sales data /Van Boeckel TP et all. Lancet Infect Dis. 2014;14(8):742-750.

3. Founou L.L., Founou R.C., Essack S.Y. Antibiotic Resistance in the Food Chain: A Developing Country-Perspective. Frontiers in Microbiology. 2016;7:1-19.

4. Manju Raj Purohit et all. Antibiotic Resistance in an Indian Rural Community: A'One-Health'Observational Study on Commensal Coliform from Humans, Animals, and Water. Int J Environ Res Public Health. 2017; 14(4): 386

5. Martínez J.L., Baquero F. Emergence and spread of antibiotic resistance: setting a parameter Space. Upsala Journal of Medical Sciences. 2014;119:68-77.

6. World Health Organization. Antimicrobial resistance Draft global action plan on antimicrobial resistance. URL: http://apps.who.int/gb/ebwha/ pdf_files/WHA68/A68_20-en.pdf?ua=1. (dated November 20, 2018).

7. Krasiy N.I. Biological properties and dynamics of formation of antibiotic resistance of microorganisms in patients with artificial lung ventilation: diss. ... Cand. Of Medical Sciences: 03.00.07 - Microbiology, Ternopil. State Medical University, Ternopil, 2016, 172.

\section{ORCID and contributionship:}

Tetiana V. Ivakhniuk: 0000-0001-5851-2218 B,D,F

Viktoriia M. Halubnycha: 0000-0002-1241-2550 C,D,F

Vladyslav A. Smiianov: 0000-0001-8164-9706 A,E,F

Lesia A. Rudenko: 0000-0003-0556-8263 C,E,F

Yevgen V. Smiianov: 0000-0003-4996-1550 B,E,F 


\section{Conflict of interest:}

The Authors declare no conflict of interest.

\section{CORRESPONDING AUTHOR}

Vladyslav A. Smiianov

Sumy State University

Rymskoho-Korsakova St., 2, 40007 Sumy, Ukraine

e-mail:v.smiyanov@med.sumdu.edu.ua

Received: 09.10.2019

Accepted: 10.05 .2020

A - Work concept and design, B - Data collection and analysis, C - Responsibility for statistical analysis,

D-Writing the article, $\mathbf{E}$-Critical review, $\mathbf{F}$ - Final approval of the article 